\title{
Association of standing and lying behavior patterns and incidence of intramammary infection in dairy cows milked with an automatic milking system
}

\author{
T. J. DeVries, ${ }^{* 1}$ J. A. Deming, ${ }^{*}$ J. Rodenburg,† G. Seguin, $\ddagger$ K. E. Leslie,§ and H. W. Barkema\# \\ *Department of Animal and Poultry Science, University of Guelph, Kemptville Campus, 830 Prescott Street, Kemptville, ON, Canada, K0G 1J0 \\ †DairyLogix Consulting, Woodstock, ON, Canada, N4S 7V8 \\ ‡Dairy Farmers of Ontario, Mississauga, ON, Canada, L5N 2L8 \\ §Department of Population Medicine, Ontario Veterinary College, University of Guelph, 50 Stone Rd E, Guelph, ON, Canada, N1G 2W1 \\ \#Department of Production Animal Health, Faculty of Veterinary Medicine, University of Calgary, Calgary, AB, Canada, T2N 4N1
}

\begin{abstract}
The standing and lying behavior patterns of dairy cows, particularly the length of time cows spend standing after milking, have the potential to influence the incidence of intramammary infection (IMI). The objectives were to describe the standing and lying behavior patterns of cows milked with an automatic milking system (AMS) and to determine how these patterns relate to the incidence of IMI. One hundred and eleven lactating Holstein dairy cows were monitored over a 4-mo period. These cows were kept in a sand-bedded freestall barn with 2 pens, each with a free cow traffic AMS. Feed was delivered once daily, and pushed up 2 to 3 times daily. Quarter milk samples were collected for bacteriological culture from each cow once every 4 wk. A new IMI was defined as a positive culture sample following a negative culture. For $7 \mathrm{~d}$ before each of the last 3 milk samplings, standing and lying behavior, and times of milking and feed manipulation (feed delivery and push up) were recorded. Daily lying time and lying bout length were negatively related with milk yield $(\mathrm{r}=-0.23$ and -0.20 , respectively $)$ and milking frequency $(\mathrm{r}=-0.32$ and -0.20 , respectively); milk yield was positively related to milking frequency $(\mathrm{r}=0.58)$. Feed manipulation near the time cows were milked (1 $\mathrm{h}$ before $2 \mathrm{~h}$ after) resulted in the longest post-milking standing times $($ mean $=86 \mathrm{~min} ; 95 \%$ confidence interval $=78,94 \mathrm{~min}$ ), whereas feed manipulation occurring outside that time frame resulted in shorter postmilking standing times. Over the study period, 171 new IMI were detected. Of these new IMI detected, those caused by coagulase-negative staphylococci were the only ones associated with post-milking standing time; as post-milking standing time increased past $2.5 \mathrm{~h}$ after milking, the odds of acquiring a new IMI tended to
\end{abstract}

Received November 23, 2010.

Accepted April 27, 2011.

${ }^{1}$ Corresponding author: tdevries@uoguelph.ca also increase. In summary, standing and lying behavior patterns of cows milked with an AMS were affected by both feed manipulation and their milking activity. Further, the post-milking standing time of cows milked with an AMS can be managed by providing fresh feed, as well as by pushing up feed, frequently throughout the day. Finally, cows that spend long periods of time $(>2.5 \mathrm{~h})$ standing following milking may be at higher risk of acquiring a new CNS IMI.

Key words: automatic milking system, mastitis, behavior, dairy cow

\section{INTRODUCTION}

Mastitis is the most common and economically significant disease that the dairy industry faces (Østerås et al., 2005). Given the complex nature of the disease, its complete control is not realistic (Smith, 1983). The identification of modifiable management practices associated with mastitis is crucial to decrease the incidence of the disease. This may be particularly important for those farms employing the use of an automatic milking system (AMS). Milk SCC may increase, and remain that way, in herds after the introduction of an AMS (Klungel et al., 2000). Similarly, SCC may be, in general, higher in AMS than in conventional parlors (Kelton et al., 2001). Interestingly, other researchers have reported no difference in SCC between AMS and conventional milking systems (Berglund et al., 2002). Further, increases in incidence of IMI and SCC are not seen in AMS when cow health status and herd management are good from the beginning of use of this type of system (Zecconi et al., 2003). It is reasonable to believe that deterioration of milk quality in well-functioning AMS due to increased bacteria and SCC are due to factors other than the AMS itself (Svennersten-Sjaunja and Pettersson, 2008).

A management practice that was associated with low SCC and low incidence of clinical mastitis in conventional systems is the prevention of cows from lying 
down immediately after milking (Peeler et al., 2000). Provision of fresh feed close to milking time is thought to stimulate cows to eat rather than to lie down, providing more time for the teat canals to close before they contact the stall surface. It has been hypothesized that the longer a cow stands after milking, the lower the risk for bacterial penetration of the teat canals when the cow eventually lies down. Presence of feed, particularly fresh feed, encourages such longer post-milking standing times (Tyler et al., 1997; DeVries and von Keyserlingk, 2005). DeVries et al. (2010) found in tie-stall housed and milked cows that the provision of feed close to milking time (between $30 \mathrm{~min}$ before to $60 \mathrm{~min}$ after) resulted in the longest post-milking standing times, as compared with feeding outside this time frame. As predicted, those cows that lie down for the first time 40 to 60 min after milking tended to have lower odds of acquiring a new environmental IMI compared with cows that lie down within $40 \mathrm{~min}$ after milking. Surprisingly, cows with post-milking standing times $>60$ min had increased odds of a new IMI. It was speculated that increased susceptibility to IMI in cows that stood for greater than $60 \mathrm{~min}$ may be due to increased teat bacterial penetrability caused by pressure created by accumulation of milk within the teat and gland sinuses (McDonald, 1975; Schultze and Bright, 1983).

For dairy herds with AMS, cows within the herd are milked individually at various frequencies, and the distribution of these milking events occurs over a 24-h period. Winter and Hillerton (1995) noted less synchrony in the behavior of AMS-milked cows, resulting in less time spent lying down. Alternatively, Hermans et al. (2003) found that AMS-milked cows had similar daily lying times to conventionally milked cows. No data exists that describes the length of time cows will stand following milking with an AMS. Thus, the objectives were to describe the standing and lying behavior patterns of cows milked with an AMS and to determine how these patterns relate to the incidence of IMI. The hypotheses were (1) that standing and lying behavior patterns are related to the milking activity patterns of these cows, (2) that those cows that go to be milked close to the time of feed manipulations (feed delivery and push up) would spend more time standing following milking, and (3) that those cows that lie down for the first time soonest after milking would be at most risk of acquiring an IMI caused by an environmental pathogen.

\section{MATERIALS AND METHODS}

\section{Farm Description}

A study was conducted with 111 lactating Holstein dairy cows (137 \pm 88 DIM; mean \pm SD; parity: $2.4 \pm$
1.5; 37 primiparous and 74 multiparous), kept in 1 of 2 groups, that were followed from June to August 2009. Each group had $62 \pm 3$ cows over the study period. It was not possible to collect data on all cows for the entire study period, as some cows were dried off; thus, complete data were obtained from 57 and 54 animals within each respective group. All cows were kept on a commercial dairy farm (Williamsburg, ON, Canada) in a freestall barn with 2 symmetrical pens (Figure 1), separated by a drive-through feed alley; each pen contained an AMS (Astronaut A2; Lely Industries NV, Maassluis, the Netherlands). Pens were arranged for free cow traffic to the AMS, with no directional gates or holding (restraint) areas. Each pen contained 60 freestalls configured in 2 rows. The 2 rows of stalls faced each another, were open at the front (head-to-head), and had a bed length of $2.55 \mathrm{~m}$. All freestalls measured $1.20 \mathrm{~m}$ wide center to center, and the neck rail was 1.14 $\mathrm{m}$ above the stall bedding surface. Stalls were deep bedded with $0.40 \mathrm{~m}$ of sand. Stalls were cleaned and raked daily and new bedding was added weekly. Rubber flooring covered the crossover alleys and the $2.0-\mathrm{m}$ space in front of the length of the feed bunk; the rest of the floor space consisted of grooved concrete. Each pen had a post-and-rail feed barrier with $0.81 \mathrm{~m} /$ cow of feeding space and 3 water troughs (each $1.8 \mathrm{~m} \times 0.5 \mathrm{~m}$; length $\times$ width). Cows were provided $18 \mathrm{~h}$ of continuous light daily; barn lights automatically turned on at $0430 \mathrm{~h}$ and turned off at $2030 \mathrm{~h}$. Cows had access to the AMS for $23 \mathrm{~h}$ daily (a 20-min milking equipment wash occurred at 0130,1240 , and $1800 \mathrm{~h}$ each day). Cows were allowed to access the AMS after $6 \mathrm{~h}$ from the previous milking, unless a milking failure occurred, in which case cows would immediately be allowed permission to be milked again. With the exception of those cows $>280$ DIM, all cows with $>12 \mathrm{~h}$ elapsed since the last milking were fetched and brought by the producer to the AMS at 0500 and $1700 \mathrm{~h}$ each day. Those cows $>280$ DIM with $>24$ h elapsed since the last milking were brought to the AMS at $0500 \mathrm{~h}$ each day. After every completed milking, cow teats were automatically sprayed with a post-milking disinfecting teat dip $(0.75 \%$ iodine; Dairyman's Defense Premier; JKR Industries Ltd., Mount Forest, Ontario, Canada).

All animals received mixed ration as well as supplemental concentrate at the AMS. The mixed ration was formulated according to the NRC (2001) nutrient requirement recommendations for high-producing dairy cows. The ration consisted of (on a DM basis) $25.2 \%$ corn silage, $34.6 \%$ haylage, $21.6 \%$ high-moisture corn, $9.5 \%$ protein and mineral supplement, $6.9 \%$ roasted soybeans, and $2.2 \%$ wheat straw. Cows were fed the ration once daily (at a level to achieve $3 \%$ orts) at $0730 \mathrm{~h}$. The ration was pushed up in the feed bunk 2 


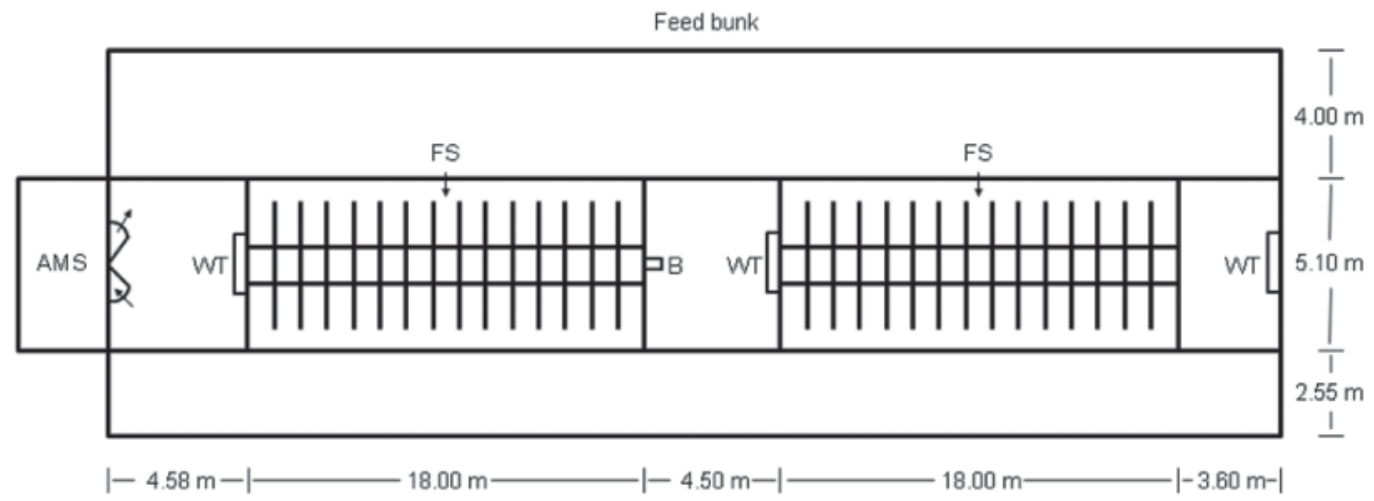

Figure 1. General layout and dimensions of each of the freestall pens. Each pen had an automatic milking system (AMS), 2 sets of head-tohead freestalls (FS), a mechanical revolving cow brush (B), and 3 water troughs (WT). Direction of cow flow in and out of the AMS is indicated with an arrow $(\rightarrow)$.

or 3 times daily. When feed was pushed up twice daily, it occurred at $1630 \mathrm{~h}( \pm 109 \mathrm{~min} ; \pm \mathrm{SD})$ and $2030 \mathrm{~h}$ ( $\pm 150 \mathrm{~min})$. When feed was pushed up 3 times daily, it occurred at $1430 \mathrm{~h}( \pm 120 \mathrm{~min}), 1800 \mathrm{~h}( \pm 50 \mathrm{~min})$ and $2200 \mathrm{~h}( \pm 131 \mathrm{~min})$. Cows received varied amounts of concentrate in the AMS (0.5 to $4.5 \mathrm{~kg} / \mathrm{d}$ ) based on the individual cow milk production and stage of lactation. The amount of concentrate apportioned at each milking was based on the elapsed time since the previous milking. Throughout all cows were managed according to the guidelines set by the Canadian Council on Animal Care (2009).

\section{Milk Sampling and Analysis}

Quarter milk samples were aseptically collected from every cow (Hogan et al., 1999) at 4-wk intervals for a total of 4 samplings from May to August 2009. Every week over that 4-mo period, approximately 1 quarter of the cows in each pen were sampled. For each milk sampling, cows were allowed to enter the AMS for milking. Once they were in the AMS, a 5-min manual hold on the milking process was initiated by a research technician. The technician then manually cleaned the teats using a paper towel. Before sampling, the first streams of milk were discarded, teat ends were disinfected with cotton swabs soaked in 70\% alcohol and allowed to dry, and then approximately $30 \mathrm{~mL}$ of milk was drawn into a sterile container. After sampling was complete and the hold on the AMS ended, the milking process (including automated udder preparation and milking) was resumed. All milk samples were frozen at $-20^{\circ} \mathrm{C}$ and later thawed and split for milk bacteriological culture and for SCC determination.

Bacterial culture was performed to identify pathogens, including Escherichia coli, Klebsiella spp., Streptococcus uberis, Streptococcus dysgalactiae, Streptococcus agalactiae, and other Streptococcus spp., as well as CNS (not differentiated into specific pathogens), Corynebacterium spp., Staphylococcus aureus, and Arcanobacterium pyogenes. This was conducted by following standardized protocols based on National Mastitis Council (NMC) guidelines for bacteriological culture and species identification (Hogan et al., 1999). In short, $10 \mu \mathrm{L}$ of milk were streaked onto blood and MacConkey bi-plates and aerobically incubated at $35^{\circ} \mathrm{C}$ for $24 \mathrm{~h}$. Colonies were enumerated (up to 10 colonies or $10+$ colonies) and speciated after $24 \mathrm{~h}$, and were then re-incubated for a further $24 \mathrm{~h}$. After $48 \mathrm{~h}$, bronopol was added to the samples and they were re-frozen (Trenholm et al., 2007) in preparation for shipping to a laboratory for SCC determination (CanWest DHI, Edmonton, Alberta, Canada). Somatic cell count analysis was conducted using the Fossomatic method (Fossomatic 4000 series; Foss Electric, Hillerød, Denmark).

Samples from which 3 or more pathogens were isolated, except those that included Staph. aureus or Strep. agalactiae, were classified as contaminated and were excluded from subsequent analyses. The NMC guidelines were used for definition of an IMI at the quarter level (Harmon et al., 1990). Occurrence of a new IMI in a quarter over a 4 -wk observation period was defined as a culture-negative sample at the beginning of the 4-wk period, followed by a sample positive at the end of the period. Non-occurrence of a new IMI was defined as 2 consecutive culture-negative samples. Therefore, quarters had to be free of IMI at the first, second, or third sampling to be considered at risk of a new IMI for the second, third, or fourth period of observation. For the same reason, a quarter experiencing a new IMI during the second or third period could not be considered at risk of becoming infected during the third or fourth period. 


\section{Standing and Lying Behavior}

Standing and lying behaviors were collected using data loggers (HOBO Pendant G Data Logger; Onset Computer Corporation, Pocasset, MA). This device measures leg orientation at 1-min intervals, and allowed all the standing and lying behavior data to be collected electronically (Ledgerwood et al., 2010). Prior to use, care was taken to synchronize the times of the AMS and the data loggers. These devices were attached to 1 of the hind legs of the cows using veterinary bandaging tape (Vetrap Bandaging Tape; 3M, London, ON, Canada) $7 \mathrm{~d}$ before each of the last 3 milk sampling events, and were removed following each milk sampling. Data collected were used to calculate standing and lying times $(\mathrm{min} / \mathrm{d})$, bout frequency (no./d), and bout length ( $\mathrm{min} /$ bout).

\section{Animal and Management Data}

All individual-cow milking-related data, including daily milking frequency, time of each milking, and yield per milking, were automatically collected and stored by the AMS. Prior to taking milk samples for the first period, each cow was scored by a research technician for lameness and cleanliness. Lameness was scored as cows exited the AMS, using a 5-point numerical gait scoring system ( $1=$ sound to $5=$ severely lame) devised by Flower and Weary (2006). Upon lameness scoring the cows, $69 \%$ were given a score of $1,30 \%$ were scored 2 , and $1 \%$ were scored 3 ; no cows were classified with a lameness score of 4 or 5 . Cleanliness was assessed using a hygiene scoring system (www.vetmed.wisc.edu/ $\mathrm{dms} /$ fapm/fapmtools/4hygiene/hygiene.pdf; Cook and Reinemann, 2007). Using this system, cows were scored on a 4-point cleanliness scale, evaluating the udder, lower legs, and upper legs-flank $(1=$ very clean to 4 $=$ very dirty). Upon cleanliness scoring the udders, $75 \%$ were scored 2 , and $25 \%$ were scored 3 ; no cows were classified with an udder cleanliness score of 1 or 4 . Upon cleanliness scoring the lower legs, $8 \%$ were given a score of $1,64 \%$ were scored $2,26 \%$ were scored 3 , and $2 \%$ were scored 4 . Upon cleanliness scoring the upper legs-flanks, $27 \%$ were given a score of $1,68 \%$ were scored 2 , and $5 \%$ were scored 3 ; no cows were classified with an upper leg-flank cleanliness score of 4 . During the week when standing and lying behavior of the cows were being monitored, the individual times of feed delivery and feed push-up were recorded by the herd manager. The time delay between milking time and the closest-in-time feed manipulation was calculated. Post-milking standing time (minutes) was calculated as the difference in time between the end of milking and the first recorded instance when the cow lies down following milking. Pre-milking standing time (minutes) was calculated as the difference in time between the end of milking and the time at which the cow stood up before milking.

\section{Statistical Analysis}

Prior to analyses, all data were screened for normality using the UNIVARIATE procedure of SAS (SAS Institute, 2008). Post-milking and pre-milking standing time, as well as individual quarter SCC, were all right skewed, and were transformed by taking their natural logarithm. All data were summarized across each of the 7-d observation periods for each cow. To characterize the relationship between observed cow-level behavioral and milking variables (lying time, lying bout frequency and length, post-milking and pre-milking standing time, milking frequency, and yield), Pearson correlations were performed using CORR procedure of SAS (SAS Institute, 2008). To determine the effect feed manipulation had on post-milking standing time, a mixed model was fitted to the data using the MIXED procedure of SAS (SAS Institute Inc., Cary, NC) treating sampling period as a repeated measure. The model included the fixed effects of delay between milking and feed manipulation, sampling period, and the interaction between these effects, and the random effects of group and cow within group. Cow within group was included in the model as the subject of the repeated statement. Compound symmetry was selected as the covariance structure on the basis of best fit according to Schwarz's Bayesian information criterion. Parity (first or mature cow), DIM, milking frequency and yield, measures of standing and lying behavior, and pre-milking standing time were introduced into the above model one at a time to assess their significance and the possible presence of confounding bias on the estimated feed manipulation-post-milking standing time relationship. For the latter, the change in the estimate of the mean effect of the feed manipulation-post-milking standing time association was evaluated and variables causing a change of $10 \%$ or more were retained as important confounding variables. Effect modification by variables on the feed manipulation-post-milking standing time association was tested by the significance in the model of an interaction term of the delay between milking time and feed manipulation and those other variables. Even though an association of pre-milking standing time with post-milking standing time was found, no interactions between these variables, or any of the other tested variables, and the delay between milking and feed manipulation were found.

To determine the association between post-milking standing time and incidence of IMI, the average post- 
milking standing time during the last $7 \mathrm{~d}$ of each sampling period was used. The hypothesized biological pathway through which post-milking standing time can affect udder health is through prevention of IMI by preventing entry through the non-closed teat canal by bacteria present in the environment of the cow. It was hypothesized that an association between post-milking standing time and IMI incidence would be detected for environmental-type bacteria. Given the high frequency of new IMI caused by both environmental- and contagious-type pathogens, pathogen-specific analyses were conducted. Occurrence or non-occurrence of a new IMI was assessed using a random intercept mixed logistic model using the GLIMMIX procedure (distribution $=$ binomial and link = logit) of SAS (SAS Institute, 2008). As new IMI were assessed at a quarter level, quarter within cow and group were considered random.

Independent variables were screened one-by-one using the described model in a bivariable analyses to identify potential covariates for multivariable modeling. The variables screened in the bivariable analyses included parity (first or mature cow), post-milking and pre-milking standing time, lying time, lying bout frequency and length, milking frequency and yield, DIM, individual quarter SCC natural logarithm, cleanliness score of the lower legs, udder, and upper legs-flank, and lameness score at the beginning of the study. For variables measured on a continuous scale, linearity of the relationship between the variable and the log odds of the occurrence of a new IMI was assessed by categorizing the continuous variable and visual inspection of plots of the odds ratio against mean values of the categories. Meaningful categories were created whenever the assumption of linearity could not be met. Variables with $P \leq 0.20$ were retained for further analyses. Multivariable analyses were performed using the above model. Average post-milking standing time was introduced as the primary variable, with possible confounding variables being retained if causing a $10 \%$ or greater change of odds ratio for the primary variable.

\section{RESULTS}

\section{Association Between Standing and Lying Behavior and Milking Activity}

Cows spent $11.2 \pm 2.5$ (mean $\pm \mathrm{SD}) \mathrm{h} / \mathrm{d}$ lying down. This lying time was dividing into $8.0 \pm 2.9$ bouts/d, which were $84.1 \pm 38.4 \mathrm{~min}$ in length. The distributions of post-milking and pre-milking standing time were right skewed. The median time to lie down for the first time following milking was 55.0 min (mean: 78.4 min; range: 1 to $926 \mathrm{~min}$ ), whereas the median time cows were standing before milking was 70.0 min (mean:

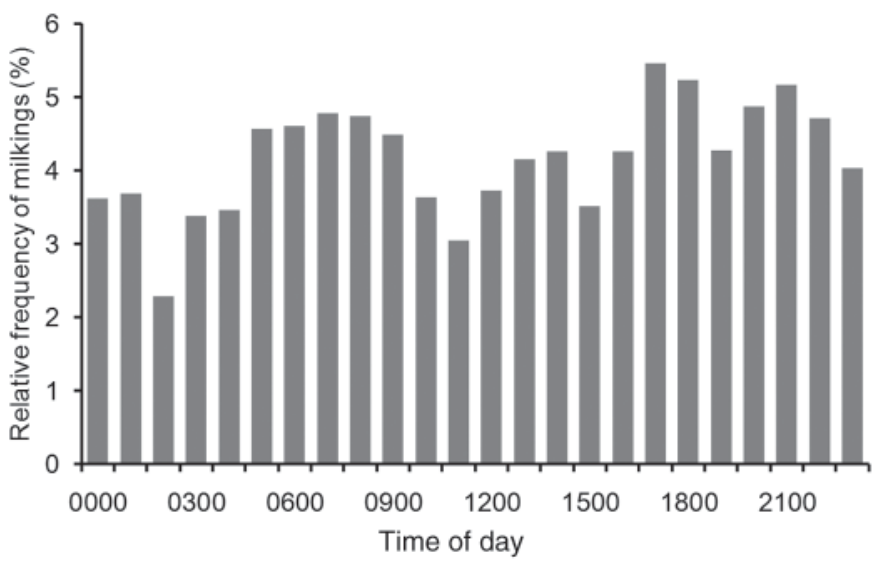

Figure 2. Relative frequencies of daily milkings per hour (\%) in the automatic milking system across the study period.

$94.2 \mathrm{~min}$, range 1 to $845 \mathrm{~min}$ ). Cows were milked 2.4 \pm 0.8 times $/ \mathrm{d}$ and produced $32.2 \pm 11.3 \mathrm{~kg} / \mathrm{d}$. The relative frequencies of milkings per hour of the day are in Figure 2.

Lying time was positively correlated $(P<0.01)$ with lying bout frequency $(\mathrm{r}=0.34)$ and length $(\mathrm{r}=0.20)$, whereas it was negatively correlated $(P<0.01)$ with post- $(\mathrm{r}=-0.39)$ and pre-milking $(\mathrm{r}=-0.60)$ standing time, milking frequency $(\mathrm{r}=-0.23)$, and milk yield $(\mathrm{r}=$ $-0.32)$. Lying bout frequency was negatively correlated $(P<0.01)$ with lying bout length $(\mathrm{r}=-0.75)$, and post- $(\mathrm{r}=-0.44)$ and pre-milking standing time $(\mathrm{r}=$ $-0.50)$. Lying bout length was positively correlated $(P$ $<0.01)$ with post- $(\mathrm{r}=0.26)$ and pre-milking standing time $(\mathrm{r}=0.19)$, and negatively correlated $(P<0.01)$ with milking frequency $(\mathrm{r}=-0.20)$ and milk yield $(\mathrm{r}$ $=-0.20)$. Post-milking standing time was positively correlated with pre-milking standing time $(\mathrm{r}=0.28$;

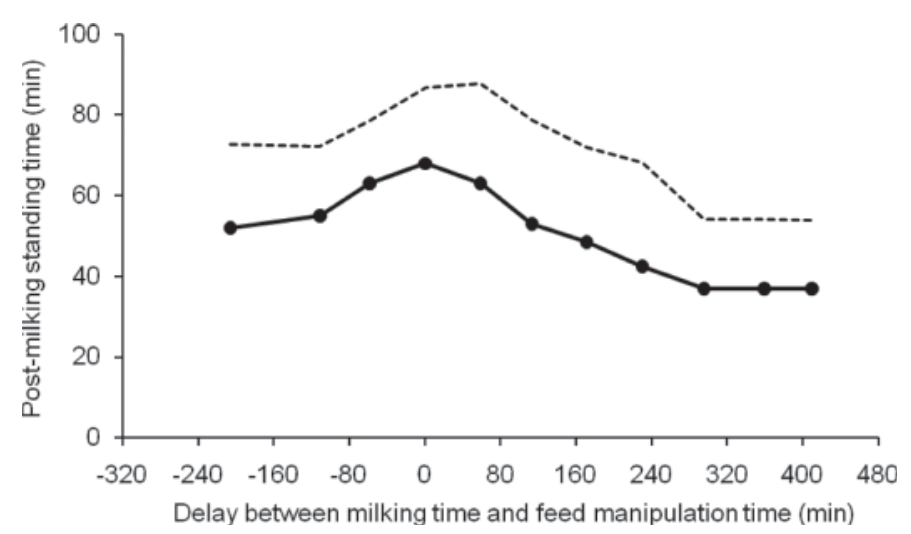

Figure 3. Moving average (with width of $60 \mathrm{~min}$ and increments of $30 \mathrm{~min}$ ) of median (solid line) and mean (dashed line) post-milking standing time across time delay between milking and feed manipulation (feed delivery and feed push up). 
$P<0.01)$. Pre-milking standing time was positively correlated with milk yield $(\mathrm{r}=0.15 ; P<0.01)$. Milking frequency was positively correlated with milk yield $(\mathrm{r}$ $=0.58 ; P<0.01)$.

\section{Association Between Feed Manipulation and Post-Milking Standing Time}

The delay in time between milking and feed manipulation (feed delivery or push up) followed an approximately normal distribution, with cows being milked $32.0 \pm 169.8$ (mean $\pm \mathrm{SD}$ ) min before feed being manipulated (range: $422 \mathrm{~min}$ before $487 \mathrm{~min}$ after feed manipulation). The relationship between cow post-milking standing time and delay between milking and feed manipulation is shown in Figure 3. This association was not linear and the delay between milking and feed manipulation was categorized based on the observed distribution; these categories were feed manipulation occurring $>60$ min before milking, $60 \mathrm{~min}$ before to $120 \mathrm{~min}$ after milking, 120 to $240 \mathrm{~min}$ after milking, and $>240$ min after milking. The distribution of post-milking standing time across categories of delay between milking and feed manipulation is illustrated in Figure 4. The time delay between milking and feed manipulation was a predictor of post-milking standing time (Table 1). The longest post-milking standing times were observed when feed manipulation occurred anywhere between 60 min before to 120 min after milking. The shortest post-milking standing times were observed when the closest feed manipulation occurred over 240 min after milking.

\section{Association Between Post-Milking Standing Time and Incidence of IMI}

Of the quarter milk samples taken, 188 pairs of milk samples were not at risk of becoming infected (82 pairs were already infected on the first of 2 consecutive samples and 1 of the samples was contaminated in 106 pairs). As a result, of the quarter milk samples taken, 1,144 pairs of samples were at risk of becoming

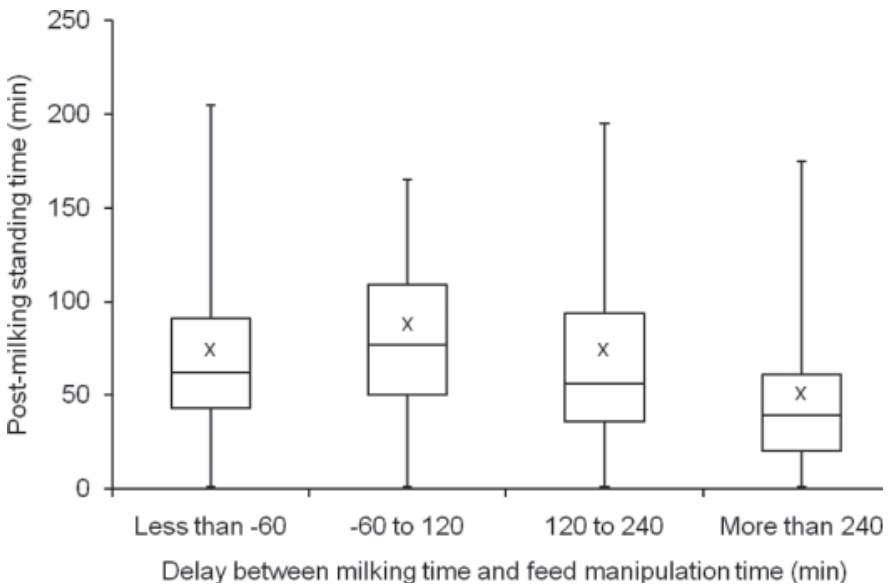

Figure 4. Box and whisker plot of post-milking standing time across time delay between milking and feed manipulation categories. Each box contains $50 \%$ of the data, the median (line), the mean (x), and the upper $(75 \%)$ and lower $(25 \%)$ quartiles. The whiskers indicate maximal and minimal values.

infected. From these paired samples, 171 new IMI were detected, including 58 new CNS IMI, 59 new Corynebacterium spp. IMI; 46 new Streptococcus spp. IMI (other than Strep. agalactiae, uberis, dysgalactiae, and canis), 3 new E. coli IMI, 2 new Klebsiella spp. IMI, 2 new A. pyogenes IMI, and 1 new Strep. uberis IMI. The herd IMI incidence rate over this time period was 1.95 new IMI/quarter-year.

Of these new IMI detected, those caused by CNS were the only ones that were associated with post-milking standing time. The relationship between incidence of CNS IMI and post-milking standing time is shown in Figure 5. A steady incidence of CNS IMI was observed up to $100 \mathrm{~min}$ of average post-milking standing time. From that point, incidence of CNS IMI decreased up to $135 \mathrm{~min}$, followed by gradually increasing until reaching a plateau past 160 min of average post-milking standing time. Non-linearity of the relationship between average post-milking standing time and risk of a new CNS IMI was clear (Figure 6). Therefore, meaningful categories were chosen for average post-milking standing times based on variable distribution and on existing

Table 1. Association between milking-feed manipulation ${ }^{1}$ delay and post-milking standing time

\begin{tabular}{lcc}
\hline & \multicolumn{2}{c}{ Post-milking standing time (min) } \\
\cline { 2 - 3 } Timing of feed manipulation & Mean & SE \\
\hline$>60$ min before milking & $75.0^{\mathrm{a}}$ & 4.03 \\
60 min before to 120 min after milking & $85.8^{\mathrm{b}}$ & 4.18 \\
120 to 240 min after milking & $74.4^{\mathrm{a}}$ & 4.29 \\
$>240$ min after milking & $51.1^{\mathrm{c}}$ & 49 \\
${ }^{\mathrm{a}-\mathrm{c}}$ Least squares means with different superscripts within a column differ $(P \leq 0.05$, adjusted for multiple com- \\
parisons using the Tukey-Kramer procedure).
\end{tabular}


Table 2. Unadjusted odds-ratio (OR) estimates of fixed-effect associations with incidence of CNS IMI (number of CNS IMI/quarter-year) for variables retained after bivariable analysis

\begin{tabular}{lccc}
\hline Variable & Mean $( \pm \mathrm{SD})$ & OR $(95 \% \mathrm{CI})$ & $P_{\text {-value }}{ }^{1}$ \\
\hline Post-milking standing time & & & 0.04 \\
$0-120 \mathrm{~min}$ & $65.6(24.1)$ & Reference & \\
$120-150 \mathrm{~min}$ & $134.0(8.5)$ & $0.26(0.04,1.96)$ & \\
$>150 \mathrm{~min}$ & $168.9(13.0)$ & $2.70(1.08,6.78)$ & 0.11 \\
Milk yield $(\mathrm{kg} / \mathrm{d})$ & $32.6(9.4)$ & $0.79(0.59,1.06)^{2}$ & 0.01 \\
DIM & $125.0(81.1)$ & $1.42(1.08,1.89)^{2}$ & 0.004 \\
LnSCC $^{3}$ & $10.9(1.6)$ & $1.58(1.15,2.06)^{2}$ & \\
\hline
\end{tabular}

${ }^{1}$ Joint $P$-value is given for multiple-class categorical variables.

${ }^{2} \mathrm{OR}$ and $95 \% \mathrm{CI}$ for 1 standard deviation increase in variable presented.

${ }^{3}$ Individual quarter SCC natural logarithm at the beginning of the study period.

knowledge about teat canal closure following milking (McDonald, 1975; Schultze and Bright, 1983). Postmilking standing time was categorized as follows: 0 to $120 \mathrm{~min}, 120$ to $150 \mathrm{~min}$, and $>150 \mathrm{~min}$.

The independent variables retained by the bivariable analyses, as well as their unadjusted association with IMI incidence are in Table 2. Three independent variables: daily milk yield, DIM at the beginning of the period, and individual quarter SCC natural logarithm at the beginning of the period were retained as confounders of the average post-milking standing time-IMI incidence association based on percentage of change of the odds ratio. None of the tested interactions were retained in the final model. Adjusted estimates obtained from the final model showed a tendency for increased risk of acquiring a new IMI as post-milking standing time increases past 150 min (Table 3).

\section{DISCUSSION}

The amount of time spent standing following milking has been widely hypothesized to affect the risk of new IMI in lactating dairy cows. Yet, the only empirical evidence for this was a study by DeVries et al. (2010) using tie-stall-housed cows. Only a limited number of researchers have calculated the amount of time dairy cows spend standing following milking. To our knowledge, this is the first report of the post-milking standing time calculated for AMS-milked cows that are housed in a freestall barn. The mean post-milking standing time was $78 \mathrm{~min}$. This is longer than that previously reported for freestall-housed cows (35 min: Tyler et al., 1997; 55 min: DeVries and von Keyserlingk, 2005; 62 min: DeVries et al., 2005). The findings of the current study support those reported for cows housed and milked in tie-stalls (79 min; DeVries et al., 2010). This observed difference in post-milking standing time between AMS and parlor-milked cows was unexpected, particularly given the amount of time the AMS-milked cows spent standing before being milked (94 min). Given that the distributions of post- and pre-milking standing time were right skewed, the median times in these values were a more appropriate comparison to those previously reported values. The median value for post-milking standing time $(55 \mathrm{~min})$ supports previously reported times for freestall-housed cows.

Given the range in post- and pre-milking standing times, and that these measures were positively correlated, it appears that several cows had extensive standing periods around the time they went to be milked. Interestingly, these cows also had lower lying bout frequencies and shorter daily lying times, which translated into shorter lying bouts. Thus, these cows would have had very long standing bouts throughout the day. Given that the behavioral patterns observed in these cows were associated with higher milk yield, it could be hypothesized that the longer standing bouts were due to longer feeding periods, and possibly larger meals. To meet the nutrient requirements for high milk production, these cows would have had to consume more feed (Bewley et al., 2010). This increased feed consumption would increase the amount of time and size of meals needed to achieve their daily feed intake

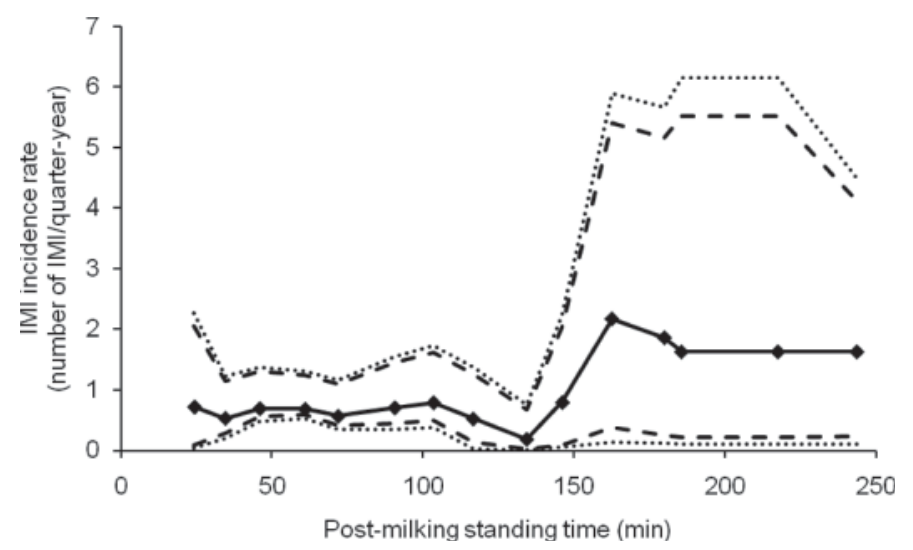

Figure 5. Moving average (with width of $60 \mathrm{~min}$ and increments of $15 \mathrm{~min}$ ) of incidence rate of CNS IMI across average post-milking standing time. The IMI incidence rate (solid line) with 90\% (dashed lines) and $95 \%$ (dotted lines) confidence limits. 
Table 3. Final logistic model of the adjusted association between average post-milking standing time and incidence of CNS IMI (number of CNS IMI/quarter-year)

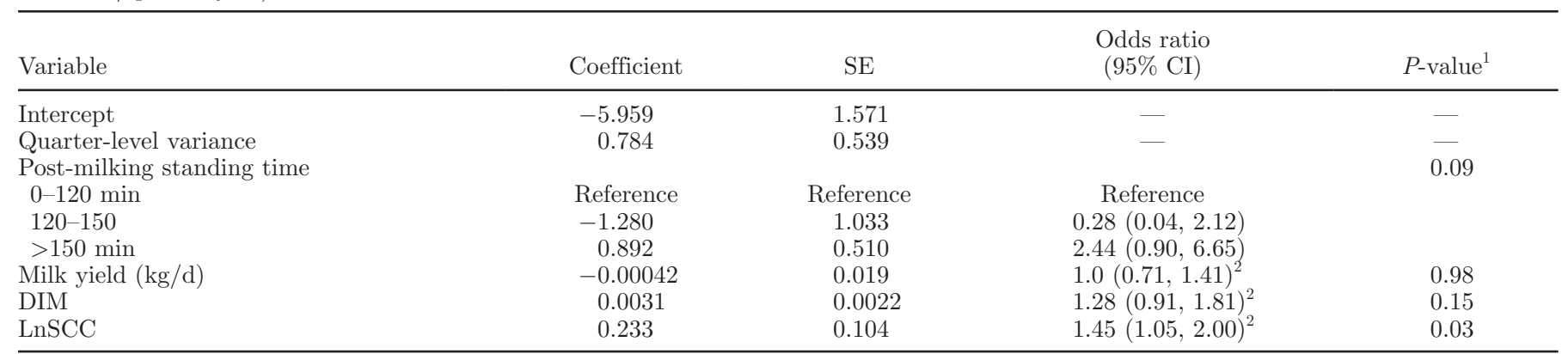

${ }^{1}$ Joint $P$-value is given for multiple-class categorical variables.

${ }^{2}$ Odds ratio and 95\% CI for one standard deviation increase in milk yield, DIM at the beginning of the sampling period, and LnSCC (individual quarter SCC natural logarithm at the beginning of the study period).

level (Dado and Allen, 1994). The negative relationship noted between milk yield and daily lying time supported that reported by others (Fregonesi and Leaver, 2001; Bewley et al., 2010). Milk yield was positively associated with milking frequency. Thus, those cows with the highest milk yield would have not only likely spent more time standing during the time they fed, but would have spent more time standing as they were milked more frequently. It is interesting to note that the average lying time and standing time observed for the AMS-milked cows in this study was similar to those for parlor milked freestall-housed cows (Wechsler et al., 2000; Cook et al., 2005; Ito et al., 2009), despite not having to wait in a holding area before milking.

Previous research with freestall-housed cows showed that the presence of feed, particularly that of freshly delivered feed, kept cows standing for longer periods of time following milking (Tyler et al., 1997; DeVries and von Keyserlingk, 2005). Because fresh feed was only delivered once daily in the study herd, with multiple feed push-ups occurring throughout the rest of the day, and milking events occurred throughout the day, it was decided to look at how all feed manipulations related to the post-milking standing time of the cows. Cows typically went to be milked near the time of feed manipulation (32 min before feed delivery or push-up), but this did vary considerably for individual cows across observation days. In support of the hypothesis that post-milking standing time would decrease as the delay between milking and feed manipulation increased, both before or after milking, feed manipulation near the time of milking (between $60 \mathrm{~min}$ before to $120 \mathrm{~min}$ after milking) resulted in the longest post-milking standing times. This finding supports previous research on freestall- (DeVries and von Keyserlingk, 2005) and tiestall-housed cows (DeVries et al., 2010). Even though feed push-up does not have the same effect of stimulating feeding activity in dairy cows as compared with fresh feed delivery (Menzi and Chase, 1994; DeVries et al., 2003; DeVries and von Keyserlingk, 2005), the results suggest that when cows go to be milked with an AMS close to the time of such manipulation, it will result in cows engaging in some level of feeding activity, and remain standing to do so. Thus, these results suggest that the post-milking standing time of cows milked with an AMS can be managed by providing fresh feed, as well as by pushing up feed, frequently throughout the day.

Unlike that reported by DeVries et al. (2010), postmilking standing time changed as the delay between milking and feed delivery time increased. The shortest post-milking standing times were observed when feed manipulation occurred over 240 min after cows were milked. Because the closest in time feed manipulation was over $4 \mathrm{~h}$ away from the time of these milkings, it suggests that these milkings were occurring in the middle of the night, a time of day when a high percentage of cows lie simultaneously (Wierenga and Hopster, 1990; Fregonesi et al., 2007) and very little feeding

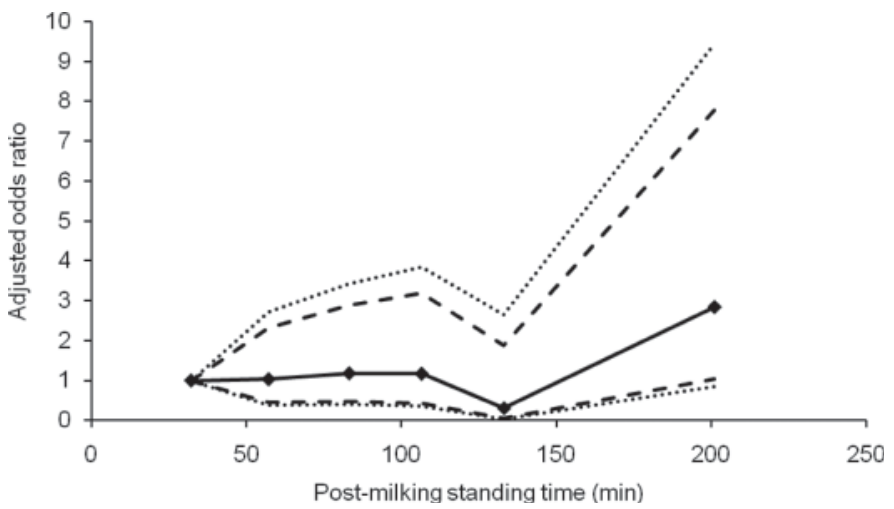

Figure 6. Adjusted estimates of the odds of acquiring a new CNS IMI across deciles of average post-milking standing time (solid line) with $90 \%$ (dashed lines) and 95\% (dotted lines) confidence limits. 
activity occurs (DeVries et al., 2003; DeVries and von Keyserlingk, 2005).

For the determination of the relationship between post-milking standing time and IMI incidence, it was hoped that the farm selected for this study would be representative in terms of udder health of commercial dairy herds typically found in Canada and northeastern parts of the United States. Yet, the bulk milk SCC $(319,000 \pm 67,000$ cells $/ \mathrm{mL}$; mean $\pm \mathrm{SD})$ was higher than a recently reported average for Ontario $(205,000$ cells/mL; Olde Riekerink et al., 2008). The herd IMI incidence rate was 1.95 new IMI/quarter-year. This was higher than the herd IMI incidence rate of 1.45 new IMI/quarter-year recently reported for tie-stall farms in that same geographical area (DeVries et al., 2010). This high rate of IMI was the result of high frequencies of new infections caused by CNS, Corynebacterium spp., and Streptococcus spp. (other than Strep. agalactiae, uberis, dysgalactiae, and canis). The high infection rate, particularly as a result of environmental pathogens, was surprising, given the use of sand bedding, which resulted in lower numbers of bacteria compared with organic bedding (Hogan et al., 1989). The high rate of CNS IMI was not unexpected because in a recent study of Canadian dairy herds, CNS was identified as the most commonly isolated family of pathogens from cows not displaying clinical signs of mastitis (Reyher et al., 2011). Additionally, CNS was reported the most common cause of IMI in cows milked in AMS (Hovinen and Pyörälä, 2011).

The only relationship detected between average post-milking standing time and incidence of IMI was for CNS. DeVries et al. (2010) associated post-milking standing time with the risk of acquiring a new IMI. In that study, the relatively low numbers of new IMI observed prevented pathogen-specific analyses from being made; however, those researchers did note that $66 \%$ of the new IMI considered were caused by CNS. Thus, is not entirely surprising that a relationship for strictly CNS existed. The incidence of CNS IMI is determined, in part, by practices related to management of the lying environment of the cow (Dufour et al., 2008). Further, it was demonstrated that bedding presence and type can affect the prevalence of CNS IMI and that this prevalence can be as high in housing situations with sand bedding as it is with organic bedding sources (Ferguson et al., 2007). Thus, it is not inconceivable that a relationship was observed between the standing behavior patterns of cows and their risk of acquiring a new CNS IMI.

The lack of relationship between average post-milking standing time and incidence of Corynebacterium spp. IMI is not unexpected because these bacteria are primarily associated with decreased milking hygiene
(Watts et al., 2000). The lack of relationship for Streptococcus spp. suggests that these bacteria were not transmitted via the lying environment, but likely came through other environmental vectors, including manure (Hogan et al., 1989) or the AMS (e.g., teat-cleaning brushes; Hovinen et al., 2005).

Interestingly, the only other significant variable in the final model associating post-milking standing time and incidence of CNS IMI was the individual quarter SCC at the beginning of the study. This variable did not interact with post-milking standing time.

The relationship between average post-milking standing time and incidence of CNS IMI was clearly nonlinear. Thus, data were divided, as in DeVries et al. (2010), into meaningful categories using knowledge of teat canal closure following milking (McDonald, 1975; Schultze and Bright, 1983). The final logistic model revealed a tendency for a relationship between post-milking standing time and occurrence of a new IMI. Similar to that demonstrated by DeVries et al. (2010), as post-milking standing time increased past $150 \mathrm{~min}$, the odds of acquiring a new IMI tended to increase as well. This result provides further evidence, as outlined by DeVries et al. (2010), for a second period of increased teat canal diameter (following the initial period that occurs right after milking), and thus bacterial penetrability, occurring after $2 \mathrm{~h}$ following milking (McDonald, 1975; Schultze and Bright, 1983).

Evidence suggests that behavior in dairy cattle changes in response to discomfort (Tucker et al., 2007). One could hypothesize that the long post-milking standing times may not be causal of the risk of a new CNS IMI, but rather a symptom of the infection. To test this, a paired $t$-test comparison was conducted on the average post-milking standing times of cows during the week before detecting a new CNS IMI and their average post-milking standing time 4 wk prior when they were not experiencing an infection. This analysis revealed no difference between these observation periods, indicating that post-milking standing time did not increase due to infection, but rather was consistent within cows over time.

Interestingly, in the present study, few cows lay down very soon (i.e., within $30 \mathrm{~min}$ ) after milking. As a result, it cannot be concluded that those cows that do lie down very quickly after milking are not at a higher risk of infection as originally hypothesized. Further research on the risk of acquiring new IMI in those cows that do lie down immediately after milking is needed to further test our hypothesis.

\section{CONCLUSIONS}

The results suggest that the standing and lying behavior patterns of cows milked with an AMS are 
affected by their milking frequency and milk yield. The reason for this association is likely the effect that milk production has on nutrient consumption levels and feeding behavior patterns. Post-milking standing time of cows milked with an AMS can be managed by providing fresh feed, as well as by pushing up feed, frequently throughout the day. The data collected do not allow us to conclude, as originally hypothesized, that those cows that lie down very quickly after milking are at a higher risk of infection. The results suggest that those cows that spend long periods of time $(>2.5$ h) standing following milking may be at higher risk of acquiring a new CNS IMI. Further research is needed to understand this relationship, particularly within the context of other types of housing and management systems that may affect cow behavior patterns and the risk of acquiring new IMI.

\section{ACKNOWLEDGMENTS}

We thank Robert Byvelds and Brabantia Farms Inc. (Williamsburg, ON, Canada) for the use of the animals and facilities. We thank Maarten Kea, Courtney Felton, Elizabeth Hooper, Carolyn Innes, and Megan Bruce of the University of Guelph, Kemptville Campus (ON, Canada) for their technical help through the data collection and summarizing periods. This research was funded through the Ontario Ministry of Agriculture, Food and Rural Affairs (OMAFRA; Guelph, ON, Canada) New Directions Research Program. This research was also financed in part by Natural Science and Engineering Research Council of Canada; Alberta Milk; Dairy Farmers of New Brunswick, Nova Scotia, Ontario, and Prince Edward Island; Novalait Inc.; Dairy Farmers of Canada; Canadian Dairy Network; Agriculture and Agri-Food Canada; Public Health Agency of Canada; Technology Prince Edward Island Inc.; Université de Montréal; and the University of Prince Edward Island, through collaboration with the Canadian Bovine Mastitis Research Network (Saint-Hyacinthe, QC, Canada). This research was also supported through contributions from the Canadian Foundation for Innovation (Ottawa, ON, Canada) and the Ontario Research Fund (Toronto, ON, Canada).

\section{REFERENCES}

Berglund, I., G. Pettersson, and K. Svennersten-Sjaunja. 2002. Automatic milking: Effects on somatic cell count and teat end-quality. Livest. Prod. Sci. 78:115-124.

Bewley, J. M., R. E. Boyce, J. Hockin, L. Munksgaard, S. D. Eicher, M. E. Einstein, and M. M. Schutz. 2010. Influence of milk yield, stage of lactation and body condition on dairy cattle lying behaviour using an automated activity monitoring sensor. J. Dairy Res. $77: 1-6$

Canadian Council on Animal Care. 2009. CCAC Guidelines on the Care and Use of Farm Animals in Research, Teaching and Testing. Canadian Council on Animal Care, Ottawa, ON, Canada.
Cook, N. B., T. B. Bennett, and K. V. Nordlund. 2005. Monitoring indices of cow comfort in free-stall-housed dairy herds. J. Dairy Sci. $88: 3876-3885$.

Cook, N. B., and D. Reinemann. 2007. A toolbox for assessing cow, udder and teat hygiene. Pages 31-43 in Proc. Natl. Mastitis Counc. Annu. Mtg. Natl. Mastitis Counc. Inc., Verona, WI.

Dado, R. G., and M. S. Allen. 1994. Variation in and relationships among feeding, chewing, and drinking variables for lactating dairy cows. J. Dairy Sci. 77:132-144.

DeVries, T. J., S. Dufour, and D. T. Scholl. 2010. Relationship between feeding strategy, lying behavior patterns, and incidence of intramammary infection in dairy cows. J. Dairy Sci. 93:1987-1997.

DeVries, T. J., and M. A. G. von Keyserlingk. 2005. Time of feed delivery affects the feeding and lying patterns of dairy cows. J. Dairy Sci. 88:625-631.

DeVries, T. J., M. A. G. von Keyserlingk, and K. A. Beauchemin. 2003. Diurnal feeding pattern of lactating dairy cows. J. Dairy Sci. 86:4079-4082.

DeVries, T. J., M. A. G. von Keyserlingk, and K. A. Beauchemin. 2005. Frequency of feed delivery affects the behavior of lactating dairy cows. J. Dairy Sci. 88:3553-3562.

Dufour, S., I. Dohoo, T. DeVries, and D. Scholl. 2008. Improving mastitis control programs through identification of risk factors related to the incidence of subclinical intramammary infections in mastitis control-From science to practice. Pages 211-218 in the Proc. 2008 Int. Conf. Mastitis Control. Wageningen Academic Publishers, Wageningen, the Netherlands.

Ferguson, J. D., G. Azzaro, M. Gambina, and G. Licitra. 2007. Prevalence of mastitis pathogens in Ragusa, Sicily from 2000 to 2006. J. Dairy Sci. 90:5798-5813.

Flower, F. C., and D. M. Weary. 2006. Effect of hoof pathologies on subjective assessments of dairy cow gait. J. Dairy Sci. 89:139-146.

Fregonesi, J. A., and J. D. Leaver. 2001. Behaviour, performance and health indicators of welfare for dairy cows housed in strawyard or cubicle systems. Livest. Prod. Sci. 68:205-216.

Fregonesi, J. A., C. B. Tucker, and D. M. Weary. 2007. Overstocking reduces lying time in dairy cows. J. Dairy Sci. 90:3349-3354.

Harmon, R. J., R. J. Eberhart, D. E. Jasper, and B. E. Langlois. 1990 Microbiological Procedures for the Diagnosis of Bovine Udder Infection. National Mastitis Council, Arlington, VA.

Hermans, G. G. N., A. H. Ipema, J. Stefanowska, and J. H. M. Metz. 2003. The effect of two traffic situations on the behavior and performance of cows in an automatic milking system. J. Dairy Sci. 86:1997-2004

Hogan, J. S., R. N. Gonzalez, R. J. Harmon, S. C. Nickerson, S. P. Oliver, J. W. Pankey, and K. L. Smith. 1999. Laboratory Handbook on Bovine Mastitis. Revised ed. National Mastitis Council Inc., Madison, WI.

Hogan, J. S., K. L. Smith, K. H. Hoblet, D. A. Todhunter, P. S. Schoenberger, W. D. Hueston, D. E. Pritchard, G. L. Bowman, L. E. Heider, B. L. Brockett, and H. R. Conrad. 1989. Bacterial counts in bedding materials used on nine commercial dairies. J. Dairy Sci. 72:250-258.

Hovinen, M., A.-M. Aisla, and S. Pyörälä. 2005. Visual detection of technical success and effectiveness of teat cleaning in two automatic milking systems. J. Dairy Sci. 88:3354-3362.

Hovinen, M., and S. Pyörälä. 2011. Udder health of dairy cows in automatic milking. J. Dairy Sci. 94:547-562.

Ito, K., D. M. Weary, and M. A. G. von Keyserlingk. 2009. Lying behavior: Assessing within- and between-herd variation in free-stallhoused dairy cows. J. Dairy Sci. 92:4412-4420.

Kelton, D. F., J. Rodenburg, and K. Hand. 2001. Udder health and milk quality on Ontario dairy farms utilizing voluntary milking systems. Pages 410-414 in Proc. 2nd Intl. Symp. Mastitis and Milk Quality, Vancouver, BC, Canada. Natl. Mastitis Counc., Madison, WI.

Klungel, G. H., B. A. Slaghuis, and H. Hogeveen. 2000. The effect of the introduction of automatic milking systems on milk quality. J. Dairy Sci. 83:1998-2003.

Ledgerwood, D. N., C. Winckler, and C. B. Tucker. 2010. Evaluation of data loggers, sampling intervals, and editing techniques 
for measuring the lying behavior of dairy cattle. J. Dairy Sci. 93:5129-5139.

McDonald, J. S. 1975. Radiographic method for anatomic study of the teat canal: Changes between milking periods. Am. J. Vet. Res. $36: 1241-1242$

Menzi, W., Jr., and L. E. Chase. 1994. Feeding behavior of cows housed in free stall barns. Pages 829-831 in Dairy Systems for the 21st Century: Proceedings of the Third International Dairy Housing Conference. American Society of Agricultural Engineers (ASAE), St. Joseph, MI.

NRC (National Research Council). 2001. Nutrient Requirements of Dairy Cattle. 7th Rev. Ed. Natl. Acad. Sci., Washington, DC.

Olde Riekerink, R. G. M., H. W. Barkema, D. F. Kelton, and D. T. Scholl. 2008. Incidence rate of clinical mastitis on Canadian dairy farms. J. Dairy Sci. 91:1366-1377.

Østerås, O., H. Hogeveen, D. K. Singh, and K. E. Leslie. 2005. Economic consequences of mastitis. Bull. Int. Dairy Fed. 394. Int. Dairy Fed., Brussels, Belgium.

Peeler, E. J., M. J. Green, J. L. Fitzpatrick, K. L. Morgan, and L. E. Green. 2000. Risk factors associated with clinical mastitis in low somatic cell count British dairy herds. J. Dairy Sci. 83:2464-2472.

Reyher, K. K., S. Dufour, H. W. Barkema, L. Des Côteaux, T. J DeVries, I. R. Dohoo, G. P. Keefe, J.-P. Roy, and D. T. Scholl. 2011. The National Cohort of Dairy Farms - A data collection platform for mastitis research in Canada. J. Dairy Sci. 94:16161626 .

SAS Institute, 2008. SAS User's Guide. Version 9.1. SAS Institute Inc., Cary, NC.

Schultze, W. D., and S. C. Bright. 1983. Changes in penetrability of bovine papillary duct to endotoxin after milking. Am. J. Vet. Res. 44:2373-2375.
Smith, K. L. 1983. Mastitis control: A discussion. J. Dairy Sci. 66:1790-1794.

Svennersten-Sjaunja, K. M., and G. Pettersson. 2008. Pros and cons of automatic milking in Europe. J. Anim. Sci. 86:37-46.

Trenholm, M. J., G. P. Keefe, and I. R. Dohoo. 2007. Effect of freezing of quarter milk samples on somatic cell count measured using flow cytometry and flouro-opto-electronic methods. Pages 234-235 in Proc. Natl. Mastitis Counc. Annu. Mtg., Harrisburg, PA. National Mastitis Council Inc., Madison, WI.

Tucker, C. B., D. E. Dalley, J.-L. K. Burke, and D. A. Clark. 2007. Milking once daily influences behavior and udder firmness at peak and mid-lactation. J. Dairy Sci. 90:1692-1703.

Tyler, J. W., L. K. Fox, S. M. Parish, J. Swain, D. L. Johnson, H. A. Grasseschi, and R. Gant. 1997. Effect of feed availability on postmilking standing time in dairy cows. J. Dairy Res. 64:617-620.

Watts, J. L., D. E. Lowery, J. F. Teel, and S. Rossbach. 2000. Identification of Corynebacterium bovis and other coryneforms isolated from bovine mammary glands. J. Dairy Sci. 83:2373-2379.

Wechsler, B., J. Schaub, K. Friedli, and R. Hauser. 2000. Behaviour and leg injuries in dairy cows kept in cubicle systems with straw bedding or soft lying mats. Appl. Anim. Behav. Sci. 69:189-197.

Wierenga, H. K., and H. Hopster. 1990. The significance of cubicles for the behaviour of dairy cows. Appl. Anim. Behav. Sci. 26:309-337.

Winter, A., and J. E. Hillerton. 1995. Behaviour associated with feeding and milking of early lactation cows housed in an experimental automatic milking system. Appl. Anim. Behav. Sci. 46:1-15.

Zecconi, A., R. Piccinini, G. Casirani, E. Binda, and L. Migliorati. 2003. Effects of automatic milking system on teat tissues, intramammary infections and somatic cell count. Ital. J. Anim. Sci. $2: 275-282$. 